\title{
ВЛИЯНИЕ СТАТИНОВ
}

И БИОЛОГИЧЕСКИХ ПРЕПАРАТОВ НА АКТИВАЦИЮ МИТОГЕНАКТИВИРОВАННЫХ ПРОТЕИНКИНАЗ У БОЛЬНЫХ РЕВМАТОИДНЫМ AРТРИТОМ

\section{Ширинский И.В. ${ }^{1}$, Козлов В.А. ${ }^{2}$, Ширинский В.С. ${ }^{1}$}

1 Лаборатория клинической иммунофармакологии ГУ НИИ клинической иммунологии СО РАМН, г. Новосибирск 2 Лаборатория регуляции иммунопоэза ГУ НИИ клинической иммунологии СО РАМН, г. Новосибирск

Резюме. Изучалось влияние биологических препаратов для лечения ревматоидного артрита (РА) и статинов на спонтанную и стимулированную активацию МАРК p38 и ERK1/2 в моноцитах больных РА. Объектом исследования являлись мононуклеары периферической крови (МНК ПК) от больных с активным РА и здоровых людей. МНК ПК культивировались в присутствии $0 ; 0,1 ; 1$ и 10 мкмоль мевастатина, 10 мкг/мл антагониста рецептора интерлейкина-1 (IL-1Ra), 5 мкг/мл инфликсимаба или 5 мкг/мл растворимого PЕGилированного p55-рецептора фактора некроза опухоли альфа (r-met$\mathrm{Hu}-\mathrm{sTNF}-\mathrm{RI}$ ). Для изучения механизмов действия мевастатина на активацию MAPK p38 и ERK1/2 в культуры добавлялся L-мевалонат. Клетки окрашивались анти-фосфо-MAPK р38 или анти-фосфоERK1/2 и анализировались на проточном цитометре. Было показано, что IL-1Ra и r-met-Hu-sTNF-RI ингибируют спонтанную активацию МАРК р38. Мевастатин уменьшал спонтанное фосфорилирование MAPK p 38 и ERK1/2. Мевастатин-индуцированное подавление активации p38 и ERK1/2 не было дозозависимым. L-мевалонат полностью предотвращал мевастатин-индуцированное уменьшение фосфорилирования MAPK p38 и частично отменял ингибирование MAPK ERK1/2. Таким образом, подавление активации МАРК является общим механизмом противовоспалительного действия статинов и некоторых биологических препаратов для лечения РА.

Ключевые слова: ревматоидный артрит, митоген-активированные протеинкиназы, статины, биологические препараты.

Shirinsky I.V., Kozlov V.A., Shirinsky V.S.

EFFECTS OF STATINS AND OTHER BIOLOGICAL PREPARATIONS UPON ACTIVATION OF MITOGEN-ACTIVATED PROTEIN KINASES IN PATIENTS WITH RHEUMATOID ARTHRITIS

Abstract. In this study, we evaluated effects of statins and other biological preparations upon spontaneous and stimulated activation of MAPK p38 and ERK1/2 in monocytes from the patients with rheumatoid arthritis (RA). We used peripheral blood mononuclear cells (PBMC) from RA patients and healthy donors. PBMC were cultured in presence of $0,0.1,1$ or $10 \mu \mathrm{M}$ mevastatin, $10 \mu \mathrm{g} / \mathrm{ml} \mathrm{IL-1} \mathrm{receptor} \mathrm{antagonist}$ (IL-1Ra), $5 \mu \mathrm{g} / \mathrm{ml}$ infliximab, and $5 \mu \mathrm{g} / \mathrm{ml}$ soluble pegylated p55 TNF- receptor (r-met-Hu-sTNF-RI). To study the mechanisms of mevastatin effects upon

Аррес для переписки:

Ширинский Иван Васильевич,

Лаборатория клинической иммунофармакологии

ГУ НИИ клинической иммунологии СО РАМН 630099, г. Новосибирск, ул. Ядринцевская, 14.

Тел.: (383) 228-25-47.

Факс: (383) 228-25-47.

E-mail: ishirinsky@mail.ru
MAPK p38 and ERK1/2 activities, L-mevalonate was added to the cultures. The cells were stained with anti-phospho-MAPK p38, or anti-phospho-ERK1/2, and analyzed with flow cytometry. We have shown that IL-1 Ra and r-met-Hu-sTNF-RI inhibited spontaneous MAPK p38 activation. Mevastatin reduced spontaneous MAPK p38 and ERK1/2 phosphorylation. Mevastatininduced suppression of MAPK p38 and ERK1/2 
activation was not dose-dependent. L-mevalonate completely prevented mevastatin-induced reduction of MAPK p38 phosphorylation and partially reversed inhibition of MAPK ERK1/2. In conclusion, decrease in MAPK activation represents a common mechanism of anti-inflammatory effects exerted by statins and some other biologicals. (Med. Immunol., vol. 11, $N$ 1, pp 71-78)

\section{Введение}

В последние годы все больший интерес исследователей вызывает изучение роли эндоплазматических сигнальных молекул в реализации хронического воспаления и разработка на этой основе противовоспалительных препаратов нового поколения. В частности, митоген-активированные протеинкиназы (МАРК) являются внутриклеточными сигнальными белками, активируются двойным фосфорилированием и принимают участие в синтезе провоспалительных цитокинов и пролиферации клеток [8]. В связи с этим ингибирование МАРК рассматривается как один из возможных походов к лечению ревматоидного артрита (РА) и других аутоиммунных заболеваний [24]. В настоящее время несколько специфичных низкомолекулярных ингибиторов МАРК проходят клинические испытания при РА.

Влияние препаратов с доказанной эффективностью на МАРК изучено мало. К наиболее эффективной терапии РА относятся ингибиторы таких провоспалительных цитокинов, как IL-1 и TNF $\alpha$ - моноклональные антитела, растворимые клеточные рецепторы или натуральные антагонисты [1]. Поскольку IL-1 и TNF $\alpha$ активируют MAPK [21], можно предположить, что одним из механизмов противовоспалительного действия антицитокиновой терапии является подавление МАРК.

Открытие противовоспалительных и иммуномодулирующих свойств ингибиторов 3-гидрокси3-метилглутарил коэнзим А редуктазы (статинов) привело к их использованию при ряде аутоиммунных заболеваний. В двойном слепом, плацебоконтролируемом исследовании показано снижение активности болезни у больных РА при использовании аторвастатина [18]. В нескольких пилотных исследованиях «до-после» продемонстрирована умеренная эффективность симвастатина при РА $[2,11]$. Известно, что статины подавляют активность RAS-ГТФаз [10], которые участвуют в активации МАРК [15]. Влияние статинов на RAS-ГTФазы опосредовано уменьшением синтеза промежуточных продуктов синтеза холестерина - изопреноидов [10]. Действие статинов на МАРК при РА не изучалось.

Клетки моноцитарного ряда играют важную роль в патогенезе ревматоидного артрита (РА), дифференцируясь в макрофаги, остеокласты идендритные клетки. Моноцитыпериферической крови (ПК) при РА находятся в активированном состоянии, что подтверждается их способностью к повышенной продукции провоспалительных цитокинов [12], синтез которых контролируется MAPK [8].

Целью настоящего исследования являлось изучение влияния биологических препаратов и статинов на активацию МАРК p38 и ERK1/2 в моноцитах ПК больных РА.

\section{Материалы и методы}

Исследование было одобрено локальным этическим комитетом нашего учреждения и все пациенты подписали форму добровольного информированного согласия. В работу включались больные с активным РА, удовлетворявшие критериям Американской коллегии ревматологов [3] и здоровые люди. В обработанные гепарином пробирки (Vacuette, Greiner Labor technik, Kremsmünster, Austria) забиралось по 20 мл венозной крови. Мононуклеары периферической крови (МНК ПК) выделялись на градиенте плотности фиколл-верографин в соответствии с методом Воуum [4]. Далее МНК ПК (1 х $10^{6} /$ мл) в течение 18 часов культивировали в среде RPMI 1640 (Sigma, CША), дополненной 0,3 мг/мл L-глютамина, 5мM HEPES-буфера, 100 мкг/мл гентамицина и $10 \%$ фетальной сыворотки телят (Sigma, CША) в присутствии $0 ; 0,1 ; 1 ;$ и $10 \mu \mathrm{M}$ мевастатина (Sigma, США), 5 мкг/мл химерных моноклональных антител к TNF $\alpha$ (инфликсимаб, Schering-Plough, США), 5 мкг/мл рекомбинантной РЕGилированной формы натурального растворимого рецептора TNF p55 тип I (r-met-Hu-sTNF-RI, Amgen, США) и 10 мкг/мл рекомбинантной, негликозилированной формы антагониста рецептора IL-1 (IL-Ra, анакинра, Amgen США). Ингибиторы цитокинов были любезно предоставлены профессором C. Dinarello, США. Для оценки влияния изопреноидов на действие мевастатина в культуры вносились L-мевалонат (Sigma, CША) в концентрации 100 мкмоль. Для изучения стимуляции фосфорилирования МАРК у больных РА и здоровых людей в культуры добавлялось 100 наноМ форбол 12-миристат 13-ацетата (PMA, Sigma, США), оценка активации МАРК проводилась через 15 минут после начала стимуляции. 
Выделение моноцитов производилось с помощью охлаждения культуральных планшетов до $0{ }^{\circ} \mathrm{C}$ в течение 30 минут. Клетки окрашивались PЕ-конъюгированными моноклональными антифосфо-МАРК p38 (T180/Y182)(BD Biosciences, США) или FITC-конъюгированными поликлональными анти-фосфо-ЕRK1/2 (T185+T202) антителами (Аbcam, Великобритания), как описано ранее [20]. Кратко, клетки фиксировали 2\% параформальдегидом, дважды отмывали в забуференном фосфатом физиологическом растворе (ЗФР) и пермеабилизовали $90 \%$ ледяным метанолом при температуре $-20{ }^{\circ} \mathrm{C}$ в течение 10 минут. Далее клетки отмывали ЗФР, блокировали $10 \%$ нормальной человеческой сывороткой и окрашивали специфическими антителами. Окрашенные клетки анализировались с помощью цитометра FACS Calibur (BD Biosciences, США). Активация МАРК p38 и ERK1/2 измерялась как медиана интенсивности флюоресценции в моноцитарном гейте.

Достоверность различий оценивалась с помощью W-критерия Уилкоксона при единичных сравнениях и с использованием метода ANOVA с поправкой Бонферрони при множественных сравнениях. Зависимость эффекта от дозы мевастатина определялась с применением пост-теста для линейного тренда. Статистическая обработка материалов исследования и построение графиков проводились с помощью программы GraphPad Prism 4, США.

\section{Результаты}

В исследование было включено 4 здоровых человека и 12 больных активным РА (средний возраст - 51 4,1 лет, средний индекс активности болезни DAS28 - 6,4 $\pm 0,3$, средняя продолжительность болезни $-8,6 \pm 1,6$ лет), получающих стандартные болезнь-модифицирующие препараты.

На рисунке 1 показано влияние стимуляции PMA на фосфорилирование МАРК р38 здоровых людей и больных РА. У здоровых людей РМА вызывал статистически значимое повышение активации МАРК р38 на 57,3\%. У больных РА усиления фосфорилирования МАРК р38 при стимуляции РМА не было выявлено.

Как видно из рисунка 2, r-met-Hu-sTNF-RI (рис. 2A и 2B) и IL-1Ra (рис. 2A и 2Г) приводили к достоверному уменьшению спонтанной активности МАРК р38 в моноцитах ПК больных РА на 77,7\% и 72,9\% соответственно. Инфликсимаб не влиял на фосфорилирование МАРК р38 (рис. 2А и 2Б).

Как показано на рисунке 3, мевастатин в концентрациях 1 и 10 мкмоль статистически значимо
A

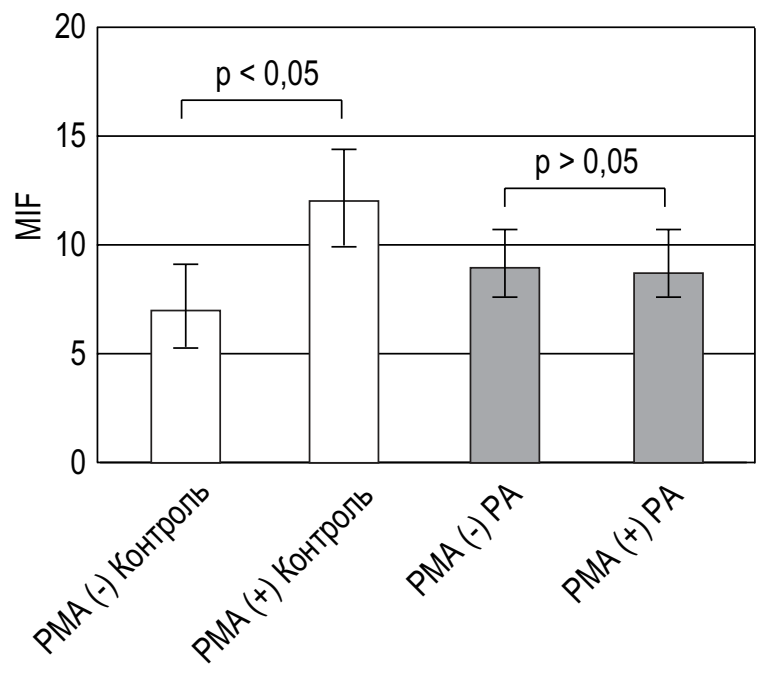

5

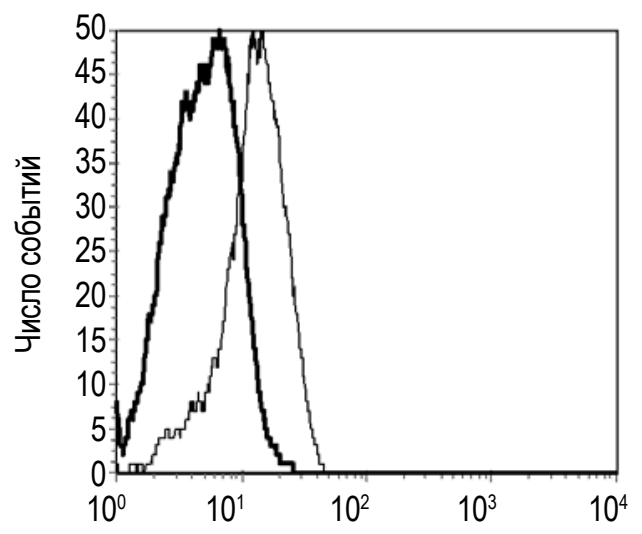

B

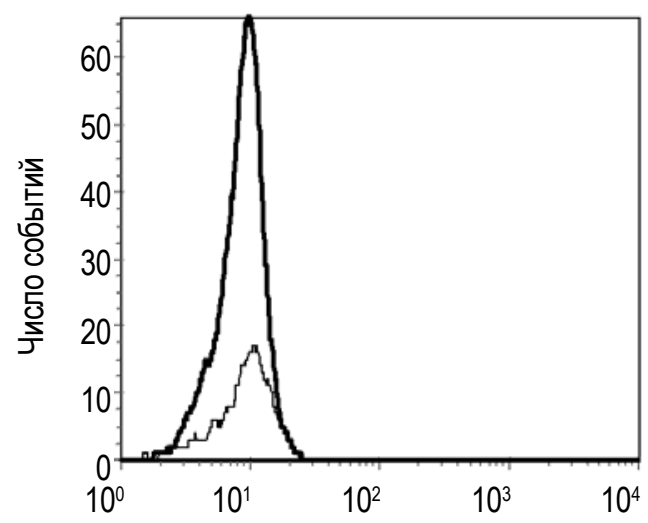

Рисунок 1. Спонтанная и РМА-стимулированная активация MAPK р38 у больных РА и здоровых (A) Представлены репрезентативные гистограммы спонтанной (Б) и РМА-стимулированной (В) активации МАРК р38. На гистограммах толстой линией обозначена нестимулированная активация МАРК р38, тонкой - стимулированная, MIF - медиана интенсивности флюоресценции. 
A

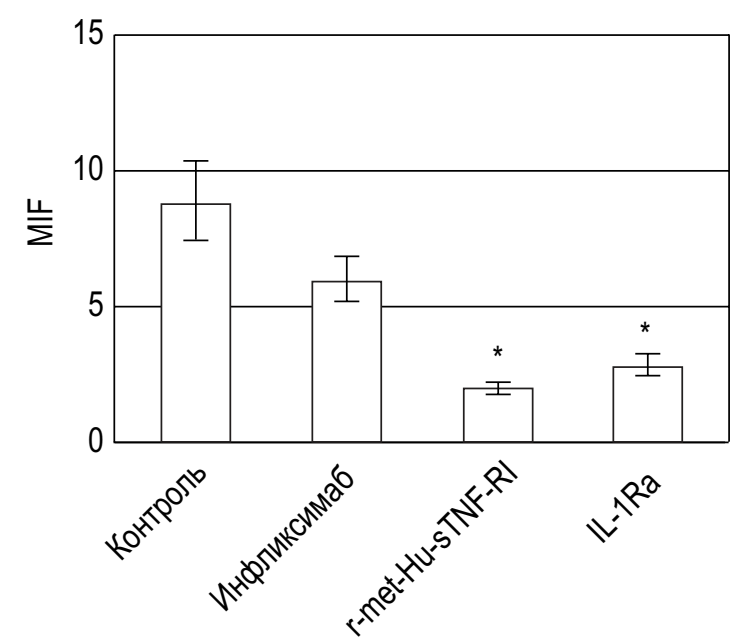

B

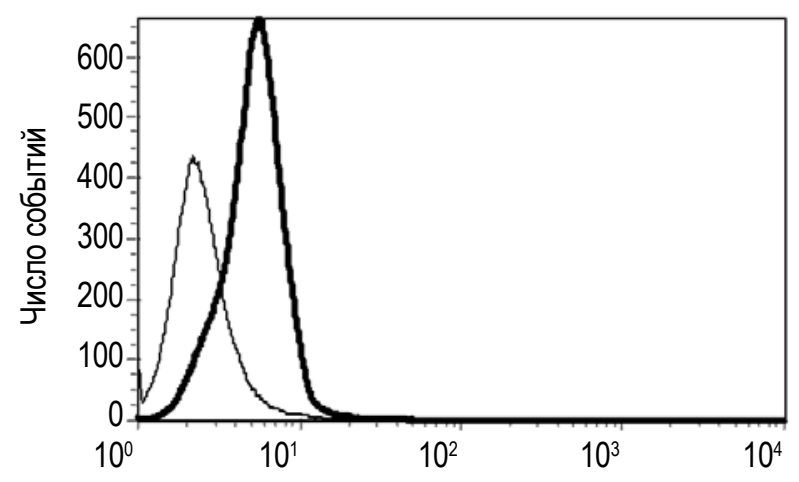

Б

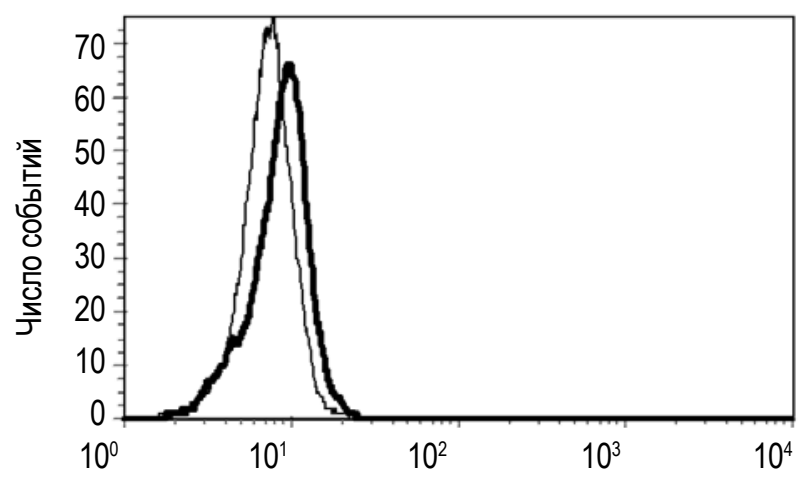

$\Gamma$

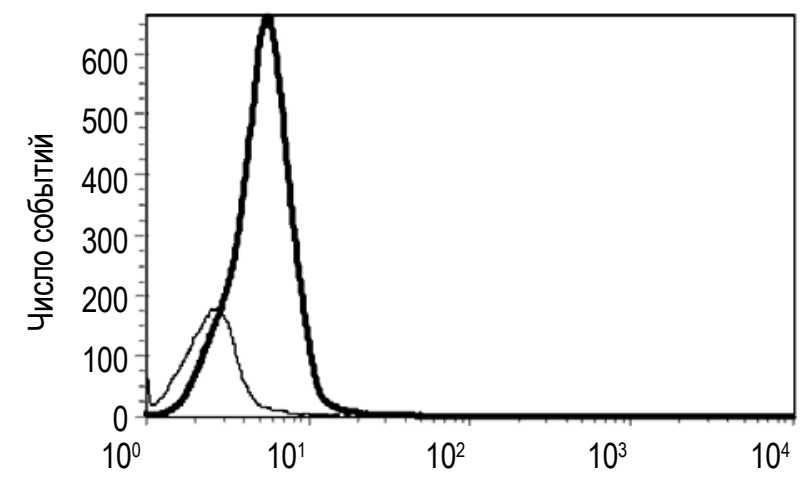

Рисунок 2. Влияние биологических препаратов на спонтанную активацию МАРК р38 у больных РА (А) Контроль - окрашенные специфическими антителами клетки без добавления антицитокиновых препаратов. Представлены репрезентативные гистограммы активации MAPK при добавлении инфликсимаба (Б), r-met-Hu-sTNF-RI (B) и IL-1Ra (Г). Ha гистограммах тонкой линией обозначена активация МАРК р38 в контроле, толстой линией - при добавлении в культуры биологического препарата. * - p $<0,05$. MIF - медиана интенсивности флюоресценции.

снижал спонтанную активацию МАРК р38 в моноцитах ПК больных РА на 18,5\% и 19\% соответственно (рис. 3А и 3В). Из рисунка 3 следует, что достоверное уменьшение фосфорилирования МАРК ERK1/2 регистрировалось при добавлении в культуры 0,$1 ; 1$ и 10 мкмоль мевастатина (на 24,3\%, $26,4 \%$ и $30,57 \%$ соответственно) (рис. 3Б и 3Г). Мевастатин-индуцированное подавление спонтанной активации МАРК р38 и ERK1/2 не было дозозависимым ( $\mathrm{p}=0,8$ и $\mathrm{p}=0,7)$. L-мевалонат полностью отменял мевастатин-индуцированное подавление спонтанного фосфорилирования MAРК p38 (на 109,1\%) (рис. 3А) и частично предотвращал уменьшение активации MAPK ERK1/2, вызванное мевастатином (на 26,7\%) (рис. 3Б).

\section{Обсуждение}

В настоящей работе было показано отсутствие активации МАРК р38 в моноцитах ПК больных РА в ответ на митоген, уменьшение спонтанной активации МАРК р38 при добавлении в культуры MHК ПК r-met-Hu-sTNF-RI и IL-Ra, подавление активации МАРК p38 и ERK1/2 мевастатином.

Исследования, изучавшие ответ моноцитов ПК больных РА на различные стимулирующие факторы, привели к противоречивым результатам. Так, Forrest et al показали двухкратное снижение LPS-стимулированной продукции TNF $\alpha$ у больных РА по сравнению с контролем [7]. B работе Rossol et al. у пациентов с PA было вы- 
A

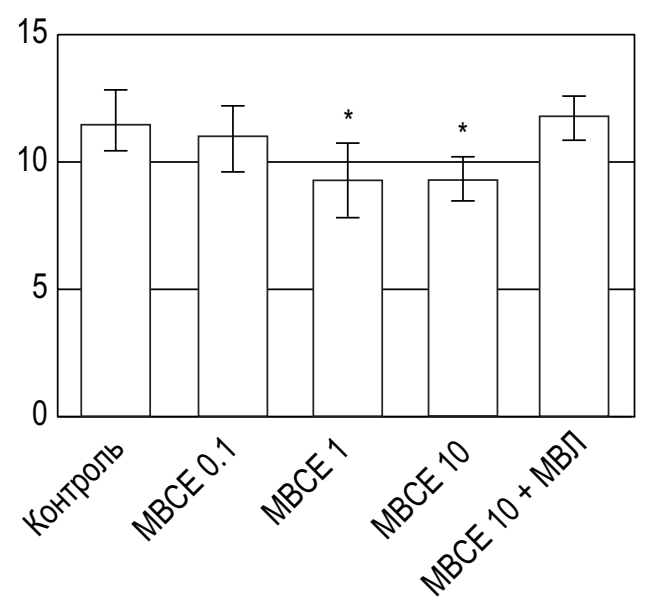

B

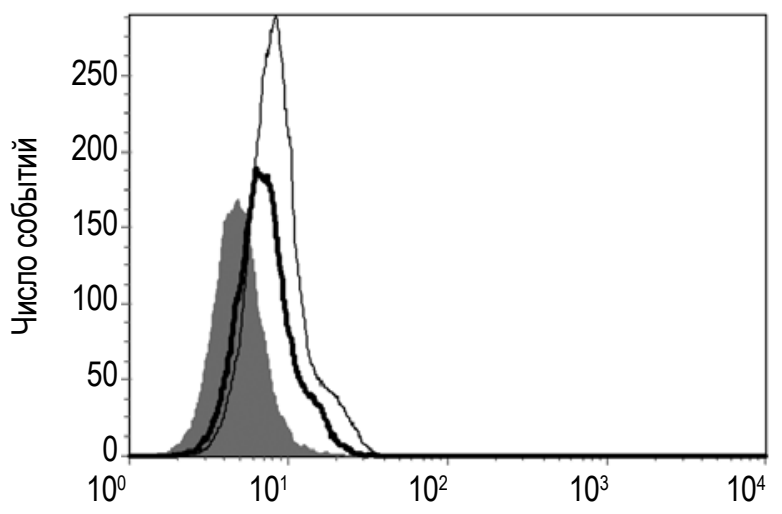

Б

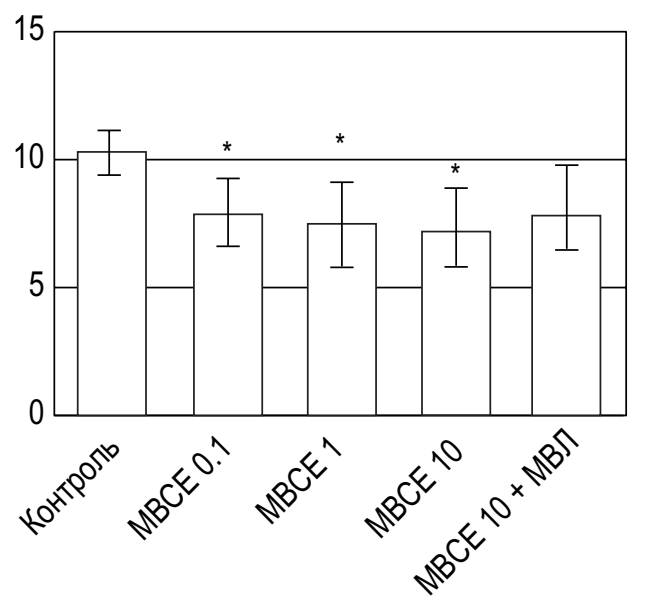

$\Gamma$

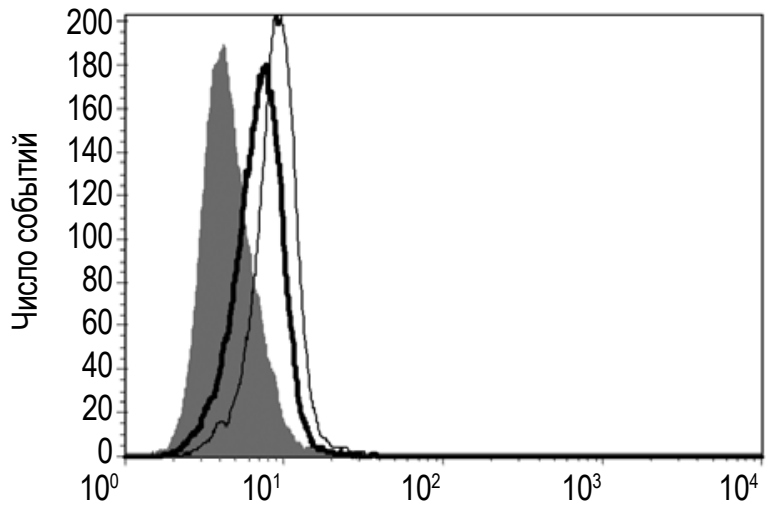

Рисунок 3. Влияние мевастатина на спонтанную активацию МАPK р38 (А) и MAPK ERK1/2 (Б)

MBCT 0,1; 1 и 10 - мевастатин в концентрациях 0,1; 1 и 10 мкмоль соответственно, МВЛ - мевалонат (100 мкмоль). Контроль окрашенные специфическими антителами клетки без добавления мевастатина. Представлены репрезентативные гистограммы активации МАРК р38 (В) и MAPK ERK1/2 (Г). На гистограммах толстой линией обозначен контроль, тонкой линией - активация МАРК при добавлении мевастатина 10 мкмоль, заполненной линией - неокрашенный контроль. ${ }^{*}-p<0,05$. MIF - медиана интенсивности флюоресценции.

явлено уменьшение индуцированного контактным взаимодействим с преактивированными T-лимфоцитами синтеза TNF $\alpha$ моноцитами ПК [22]. В исследовании Fabris et. al сниженный ответ на LPS выявлялся только у больных с ранним РА [6]. В тоже время в ряде работ показано, что моноциты при РА находятся в активированном состоянии [16, 26, 27]. Можно предположить, что выявленное в нашем исследовании отсутствие ответа на РМА обусловлено персистирующей активацией МАРК в моноцитах больных с активным РА.

Ингибирующее действие r-met-Hu-sTNF-RI и отсутствие влияния инфликсимаба на спонтанную активацию МАРК р38 можно объяснить бо- лее низкой аффинностью к TNF $\alpha$ моноклональных антител по сравнению с r-met-Hu-sTNF-RI $[5,17,23]$. Другим объяснением полученных данных может быть способность r-met-Hu-sTNF-RI, кроме TNF $\alpha$, ингибировать лимфотоксин- $\alpha$.

В работах, изучавших влияние статинов на активацию МАРК, получены противоречивые результаты. Так, в исследовании Li et al. аторвастатин не влиял на активацию МАРК ERK в клетках гладкой мускулатуры быка, ноприводил кядерной транслокации МАРК ERK [14]. Senokuchi et. al. продемонстрировали подавление статинами GM-CSF-индуцированной активации перитонеальных макрофагов мыши [25]. Симвастатин не оказывал влияния на путь MAPK ERK1/2 
в клетках гладкой мускулатуры человека [30], ловастатин подавлял фенилэфрин-индуцированное фосфорилирование МАPK ERK1/2 в кардиомиоцитах новорожденных крыс [19], некоторые статины активировали МАPK ERK1/2 и MAPK p38 в макрофагах [32]. Противоречивость данных можно объяснить использованием различных статинов, различными клетками-мишенями и разными внутриклеточными путями активации МАРК в каждой экспериментальной модели.

МАРК р38 играет важную роль в развитии и поддержании воспаления при РА [24], поскольку участвует в продукции многих провоспалительных цитокинов [28]. Статин-индуцированное подавление МАРК p38, выявленное в нашем исследовании, может быть основным механизмом снижения уровней сывороточного IL-6 у больных PA, получающих лечение аторвастатином [18] и уменьшения продукции IL-6 и IL-8 синовиоцитами больных РА, культивированными в присутствии симвастатина [13].

MAPK ERK1/2 участвует в пролиферации клеток и продукции синовиолина [9], который является основной молекулой системы деградации эндоплазматического ретикулума (endoplasmic reticulum associated degradation, ERAD). Было показано, что гиперактивация ERAD-системы является важным звеном патогенеза PA [31]. Повышенное содержание синовиолина в МНК ПК ассоциировано с рефрактерностью к терапии инфликсимабом [29]. Можно предположить, что подавление статинами активации МАPK ERK1/2 в моноцитах приводит к ингибированию ERADсистемы и уменьшению активности PA.

Таким образом, r-met-Hu-sTNF-RI и IL-1Ra, но не инфликсимаб уменьшают спонтанную активацию МАРК р38 в моноцитах ПК больных РА. Мевастатин подавляет активацию МАРК р38 и ERK1/2 вследствие снижения синтеза изопреноидов. Это влияние статинов на внутриклеточные сигнальные молекулы может объяснять их противовоспалительные эффекты при РА, механизмы которых сходны с действием биологических препаратов.

\section{Благодарности}

Авторы благодарят професcopa C. Dinarello за предоставленные реагенты.

\section{Список литературы}

1. Ширинский И.В., Малышева О.А., Ширинский В.С. Цитокиновая и антицитокиновая терапия ревматоидного артрита и рассеянного склероза // Медицинская иммунология. - 2001. № 3. - С. 401-414.

2. Ширинский И.В., Желтова О.И., Соловьева Н.Ю., Ширинский В.С., Козлов В.А. Клиническая эффективность статинов при ревматоидном артрите - пилотное исследование // Медицинская иммунология. - 2007. - № 4-5. С. 505-508.

3. Arnett F.C., Edworthy S.M., Bloch D.A., McShane D.J., Fries J.F., Cooper N.S., Healey L.A., Kaplan S.R., Liang M.H., Luthra H.S., et al. The American Rheumatism Association 1987 revised criteria for the classification of rheumatoid arthritis // Arthritis Rheum. - 1988. - Vol. 31. - P. 315-324.

4. Boyum A. Isolation of leucocytes from human blood. A two-phase system for removal of red cells with methylcellulose as erythrocyte-aggregating agent // Scand. J. Clin. Lab. Invest., Suppl. - 1968. Vol. 97. - P. 9-29.

5. Edwards C.K., 3rd. PEGylated recombinant human soluble tumour necrosis factor receptor type I (r-Hu-sTNF-RI): novel high affinity TNF receptor designed for chronic inflammatory diseases // Ann. Rheum. Dis. - 1999. - Vol. 58, Suppl. 1. P. I73-181.

6. Fabris M., Tolusso B., Di Poi E., Tomietto P., Sacco S., Gremese E., Ferraccioli G. Mononuclear cell response to lipopolysaccharide in patients with rheumatoid arthritis: relationship with tristetraprolin expression // J. Rheumatol. - 2005. - Vol. 32. P. 998-1005.

7. Forrest C.M., Harman G., McMillan R.B., Stoy N., Stone T.W., Darlington L.G. Modulation of cytokine release by purine receptors in patients with rheumatoid arthritis // Clin. Exp. Rheumatol. 2005. - Vol. 23. - P. 89-92.

8. Gallin J., Snyderman R., Agents targeting transcription factors // Inflammation / ed. Fearon D.T., Barton F.H., Nathan C., Lippincot Williams \& Wilkins, 1999. - P. 1159-1176.

9. Gao B., Calhoun K., Fang D. The proinflammatory cytokines IL-1beta and TNFalpha induce the expression of Synoviolin, an E3 ubiquitin ligase, in mouse synovial fibroblasts via the Erk1/2-ETS1 pathway // Arthritis Res Ther. 2006. - Vol. 8. - P. R172.

10. Greenwood J., Steinman L., Zamvil S.S. Statin therapy and autoimmune disease: from protein prenylation to immunomodulation // Nat. Rev. Immunol. - 2006. - Vol. 6. - P. 358-370.

11. Kanda H., Hamasaki K., Kubo K., Tateishi S., Yonezumi A., Kanda Y., Yamamoto K., Mimura T. Antiinflammatory effect of simvastatin in patients 
with rheumatoid arthritis // J. Rheumatol. - 2002. Vol. 29. - P. 2024-2026.

12. Kinne R.W., Brauer R., Stuhlmuller B., Palombo-Kinne E., Burmester G.R. Macrophages in rheumatoid arthritis // Arthritis Res. - 2000. Vol. 2. - P. 189-202.

13. Lazzerini P.E., Lorenzini S., Selvi E., Capecchi P.L., Chindamo D., Bisogno S., Ghittoni R., Natale M.R., Caporali F., Giuntini S., Marcolongo R., Galeazzi M., Laghi-Pasini F. Simvastatin inhibits cytokine production and nuclear factor-kB activation in interleukin 1beta-stimulated synoviocytes from rheumatoid arthritis patients // Clin. Exp. Rheumatol. - 2007. - Vol. 25. P. 696-700.

14. Li M., Liu Y., Dutt P., Fanburg B.L., Toksoz D. Inhibition of serotonin-induced mitogenesis, migration, and ERK MAPK nuclear translocation in vascular smooth muscle cells by atorvastatin // Am J Physiol Lung Cell Mol Physiol. - 2007. Vol. 293. - P. L463-471.

15. Lim L., Manser E., Leung T., Hall C. Regulation of phosphorylation pathways by p21 GTPases. The p21 Ras-related Rho subfamily and its role in phosphorylation signalling pathways // Eur. J. Biochem. - 1996. - Vol. 242. - P. 171-185.

16. Liote F., Boval-Boizard B., Weill D., Kuntz D., Wautier J.L. Blood monocyte activation in rheumatoid arthritis: increased monocyte adhesiveness, integrin expression, and cytokine release // Clin. Exp. Immunol. - 1996. - Vol. 106. P. 13-19.

17. Loetscher H., Gentz R., Zulauf M., Lustig A., Tabuchi H., Schlaeger E.J., Brockhaus M., Gallati H., Manneberg M., Lesslauer W. Recombinant 55-kDa tumor necrosis factor (TNF) receptor. Stoichiometry of binding to TNF alpha and TNF beta and inhibition of TNF activity // J. Biol. Chem. - 1991. - Vol. 266. P. 18324-18329.

18. McCarey D.W., McInnes I.B., Madhok R., Hampson R., Scherbakov O., Ford I., Capell H.A., Sattar N. Trial of Atorvastatin in Rheumatoid Arthritis (TARA): double-blind, randomised placebocontrolled trial // Lancet. - 2004. - Vol. 363. P. 2015-2021.

19. Melchert R.B., Liu H., Granberry M.C., Kennedy R.H. Lovastatin inhibits phenylephrineinduced ERK activation and growth of cardiac myocytes // Cardiovasc Toxicol. - 2001. - Vol. 1. P. 237-252.

20. Montag D.T. Successful development of a flow cytometric assay to analyze cytokine-induced phosphorylation pathways [CIPP] within peripheral blood leukocytes. Dissertation. Pittsburgh. - 2003. P. 123.

21. Rossa C., Ehmann K., Liu M., Patil C., Kirkwood K.L. MKK3/6-p38 MAPK signaling is required for IL-1beta and TNF-alpha-induced RANKL expression in bone marrow stromal cells // J. Interferon Cytokine Res. - 2006. - Vol. 26. P. 719-729.

22. Rossol M., Kaltenhauser S., Scholz R., Hantzschel H., Hauschildt S., Wagner U. The contactmediated response of peripheral-blood monocytes to preactivated $\mathrm{T}$ cells is suppressed by serum factors in rheumatoid arthritis // Arthritis Res Ther. - 2005. Vol. 7. - P. R1189-1199.

23. Scallon B.J., Trinh H., Nedelman M., Brennan F.M., Feldmann M., Ghrayeb J. Functional comparisons of different tumour necrosis factor receptor / IgG fusion proteins // Cytokine. - 1995. Vol. 7. - P.759-770.

24. Schett G., Zwerina J., Firestein G. The p38 mitogen-activated protein kinase (MAPK) pathway in rheumatoid arthritis // Ann. Rheum. Dis.2008. - Vol. 67. - P. 909-916.

25. Senokuchi T., Matsumura T., Sakai M., Yano M., Taguchi T., Matsuo T., Sonoda K., Kukidome D., Imoto K., Nishikawa T., KimMitsuyama S., Takuwa Y., Araki E. Statins suppress oxidized low density lipoprotein-induced macrophage proliferation by inactivation of the small $G$ protein-p38 MAPK pathway // J. Biol. Chem. - 2005. - Vol. $280-$ P. 6627-6633.

26. Shinohara S., Hirohata S., Inoue T., Ito K. Phenotypic analysis of peripheral blood monocytes isolated from patients with rheumatoid arthritis // J. Rheumatol. - 1992. - Vol. 19. - P.211-215.

27. Stuhlmuller B., Ungethum U., Scholze S., Martinez L., Backhaus M., Kraetsch H.G., Kinne R.W., Burmester G.R. Identification of known and novel genes in activated monocytes from patients with rheumatoid arthritis // Arthritis Rheum. 2000. - Vol. 43. - P. 775-790.

28. Suzuki M., Tetsuka T., Yoshida S., Watanabe N., Kobayashi M., Matsui N., Okamoto T. The role of $\mathrm{p} 38$ mitogen-activated protein kinase in IL-6 and IL-8 production from the TNFalpha- or IL-1beta-stimulated rheumatoid synovial fibroblasts // FEBS Lett. - 2000. - Vol. 465. P. 23-27.

29. Toh M.L., Marotte H., Blond J.L., Jhumka U., Eljaafari A., Mougin B., Miossec P. Overexpression of synoviolin in peripheral blood and synoviocytes from rheumatoid arthritis patients and continued elevation in nonresponders to infliximab treatment // Arthritis Rheum. - 2006. - Vol. 54. - P. 2109-2118. 
30. Turner N.A., O’Regan D.J., Ball S.G., Porter K.E. Simvastatin inhibits MMP-9 secretion from human saphenous vein smooth muscle cells by inhibiting the RhoA / ROCK pathway and reducing MMP-9 mRNA levels // FASEB J. - 2005. Vol. 19. - P. 804-806.

31. Yamasaki S., Yagishita N., Tsuchimochi K., Nishioka K., Nakajima T. Rheumatoid arthritis as a hyper-endoplasmic-reticulum-associated degradation disease // Arthritis Res Ther. - 2005. Vol. 7. - P. 181-186.
32. Yano M., MatsumuraT., SenokuchiT., Ishii N., Murata Y., Taketa K., Motoshima H., Taguchi T., Sonoda K., Kukidome D., Takuwa Y., Kawada T., Brownlee M., Nishikawa T., Araki E. Statins activate peroxisome proliferator-activated receptor gamma through extracellular signal-regulated kinase $1 / 2$ and p38 mitogen-activated protein kinase-dependent cyclooxygenase-2 expression in macrophages // Circ. Res. - 2007. - Vol. 100. - P. 1442-1451.

поступила в редакцию 30.09.2008 принята к печати 25.10.2008 